\title{
Representatividade lesbiana na obra Amora, De Natalia Borges \\ Polesso
}

\author{
Representatividad lesbiana en la obra "Amora", de Natalia Borges \\ Polesso
}

Representativeness lesbian in the book "Amora", from Natalia Borges

Polesso

\author{
Ana Valéria Goulart dos Santos_ ${ }^{1}$
}

\begin{abstract}
Resumo
Há uma grande carência de obras literárias e escritores LGBTTQI (Lésbicas, Gays, Bissexuais, Travestis, Transexuais, Queer, Intersexuais), tirando algumas exceções de escritores gays e livros com personagens gays, é muito difícil encontrar no mercado livros com essa temática e, ainda mais raro, escritores assumidamente LGBT que conseguem escrever e publicar suas obras. Assim, a proposta deste artigo é trazer à tona uma discussão sobre a homossexualidade feminina retratada de uma forma livre de estereótipos, como na obra Amora, da autora gaúcha Natalia Borges Polesso. Além disso, também se propõe uma reflexão sobre as relações sociais e afetivas dessas protagonistas mulheres. Vale salientar que a autora é lesbiana e a temática de todos os contos também são. A minibiografia da escritora na obra não aponta esse dado pessoal de extrema relevância para a representatividade de uma parcela da população leitora, a informação, portanto, foi obtida por meio de pesquisas. Partindo da ideia de que a produção literária é um ato também político, um livro com temática homoafetiva feminina escrito por uma mulher lesbiana é imprescindível para a sociedade e, ainda assim, muito difícil de se encontrar, ainda que hajam escritoras e escritores produzindo (mesmo não sendo um número significante) e um público buscando essas obras, pra se enxergar representados na literatura.
\end{abstract}

Palavras-chave: Literatura; lesbianidade; representatividade; visibilidade.

\section{Resumen}

Hay una gran carencia de obras literarias y escritores LGBTTQI (Lesbianas, Gays, Bisexuales, Travestis, Transexuales, Queer, Intersexuales), tomando algunas excepciones de escritores gays y libros con personajes gays, es muy difícil encontrar en el mercado libros con esta temática y, aún más raro, escritores asumidos LGBT que consiguen escribir y publicar sus obras. Así, la propuesta de este artículo es traer a la luz una discusión sobre la homosexualidad femenina retratada de una manera libre de estereotipos, como en la obra "Amora", de la autora gaucha Natalia Borges Polesso. Además de esto, también se propone una reflexión sobre relaciones sociales y afectivas de estas protagonistas mujeres. Vale subrayar que la escritora es lesbiana y la temática de todos los cuentos también son. La mini biografía de la autora de la obra no apunta este dato personal de extrema relevancia para la representatividad de una parcela de la populación lectora, la información, por lo tanto fue obtenida por medio de pesquisas. Partiendo de la idea que la producción literaria es un acto también político, un libro con temática homoafetiva femenina escrito por una mujer lesbiana es imprescindible para la sociedad y, aun así, muy difícil de encontrar, aunque haya escritoras y escritores producido (mismo no siendo un número significante) y un público buscando estas obras, para verse representados en la literatura.

Palabras claves: Literatura; lesbianidade; representatividade; visibilidade.

\footnotetext{
${ }^{1}$ Graduanda de Licenciatura em Letras Português/Espanhol e respectivas literaturas; Unipampa; Jaguarão, Rio Grande do Sul, Brasil; anavaleriagoulart@gmail.com.
} 


\begin{abstract}
There is a great shortage of literary works and writers LGBTTQI (Lesbians, Gay, Bisexual, Transvestite, Transsexual, Queer, Intersex), taking some exceptions from gay writers and books with gay characters, it is very difficult to find books on this subject on the market and, even rarer, overtly LGBT writers who can write and publish their works. Thus, the proposal of this article is to bring up a discussion about female homosexuality portrayed in a stereotype-free way, as in the "Amora" work by the author Natalia Borges Polesso. In addition, it is also proposed a reflection on the social and affective relations of these female protagonists. It is worth noting that the author is a lesbian and the subject matter of all short stories are. The mini-biography of the writer in the work does not point to this personal data of extreme relevance for the representativeness of a portion of the reading population, the information, therefore, was obtained through research. Starting with the idea that literary production is a political act, a female-themed homoafetiva book written by a lesbian woman is indispensable for society and yet very difficult to find, even though there are writers and writers producing not being a significant number) and an audience seeking these works, to see themselves represented in literature.
\end{abstract}

Keywords: Literature; lesbianism; representativeness; visibility.

\title{
1. Introdução
}

A obra a que se destina este artigo intitula-se Amora, da escritora gaúcha Natalia Borges Polesso, doutora em Teoria da Literatura, é autora dos livros Recortes para álbum de fotografia sem gente (2013), vencedor do prêmio Açorianos de Literatura, na categoria contos, no ano de 2013, Coração a corda (2015), da tirinha tosca A escritora incompreendida, publicada exclusivamente na internet, e o livro no qual este artigo se debruça, Amora (2015), vencedor dos prêmios AGES - livro do ano, Açorianos de Literatura na categoria contos $2016,1^{\circ}$ lugar no Prêmio Jabuti categoria contos e crônicas, além do prêmio Jabuti Escolha do Leitor.

Amora é um livro de contos, publicado em 2015, pela Editora Dublinense, sob o selo Não Editora, possui um projeto gráfico muito requintado, característica que encanta os olhos do leitor que ainda nem o leu. É prefaciado por Paloma Vidal, que evidencia a invisibilização da mulher lesbiana na sociedade, da sensação de não-pertencimento, como se estivessem sempre à margem da sociedade e de lá não pudessem sair, Paloma, termina o prefácio escrevendo sobre a naturalidade da escrita de Natalia Borges Polesso, que promove uma reflexão no leitor sobre essa condição natural no ser humano, de ser afetuoso com outro ser humano, seja ele quem for, sem que o sexo biológico ou o gênero construído socialmente sejam pré-requisitos.

Assim, pode-se afirmar com segurança que o livro, embora verse a respeito de relações lesbianas em distintos estágios da vida humana, fala muito mais do que apenas a homossexualidade feminina. A obra explora o universo infantil, juvenil, adulto e idoso, esquece dos padrões já conhecidos e estereotipados de como "sair do armário" e retrata suas personagens de forma comum, em situações cotidianas, frequentemente vividas em histórias onde os protagonistas são casais homossexuais. 
A autora sabe usar a linguagem artisticamente lapidando todas as palavras, expressões e imagens poéticas, transparecendo a harmonia e beleza que formam um estilo próprio para a sua escrita neste livro. Em entrevista, a autora revela que esta obra foi uma experiência de coisas nunca anteriormente escrita por ela. Natalia consegue promover uma quebra de expectativas muito positiva no que tange ao estereótipo sobre literatura LGBT e pessoas LGBT, sobre tudo mulheres lésbicas, tema que ao ser pesquisado no google, por exemplo, resulta somente em produtos de erotização feito para o consumo do público masculino, o que é um reflexo perfeito da mentalidade de uma enorme parcela da sociedade brasileira que tem como base o patriarcado.

O livro possui trinta e três contos narrativos, por isso, foram escolhidos apenas 3 para estudar. Todas as narrativas se diferenciam entre si, tendo apenas um ponto em comum, o protagonismo de mulheres em torno da lesbianidade. De restante, se singularizam na forma estrutural, indo de e-mails até uma escrita menor e mais lírica, abordam a descoberta da sexualidade, traição, suicídio, termino de relacionamento, velhice e outros, a escritora também é plural no que tange à faixa etária das personagens, pois tem-se retratado desde o período da infância até a $3^{\mathrm{a}}$ idade.

Um ponto importante a ser comentado é sobre a escolha do termo lesbiana e lesbianidade em vez de lésbica e lesbianismo. Devido ao fato de estas duas últimas terminologias terem sido largamente utilizadas no século XIX, com forma de patologizar essas mulheres no discurso científico da época. Embora, hoje em dia o termo lésbica ainda seja utilizado, e sem essa conotação, o artigo optou por não usa-la como forma de postura política militante.

\section{Contextualização dos contos}

Os contos escolhidos foram: 1) "Flor, flores, ferro retorcido"; 2) "Marília acorda"; 3) "Amora". A primeira narrativa fala sobre a relação da vizinhança com uma mulher lesbiana sob a perspectiva de uma criança, agora já adulta, ou seja, ela relembra, depois de um tempo, as coisas da sua infância. Num almoço de família a menina escuta a palavra machorra e isso a incomoda, pois ela não sabe o significado dessa palavra, ao questionar os adultos a sua volta, eles demonstram inquietude e perplexidade com o assunto e desconversam falando que na verdade eles tinham dito a palavra cachorra, a partir de então a ignoraram. Porém a menina sabia que não estava equivocada, continuou a prestar atenção nas conversas, dessa vez sem deixar que ninguém percebesse isso e, descobriu que a palavra era designada para identificar a 
vizinha. Como o significado dessa palavra lhe era desconhecido, começou uma jornada para tentar compreendê-lo.

O segundo conto aborda a relação homoafetiva de duas senhoras idosas, casadas já há muito tempo e, que tentam lidar com a questão do envelhecimento e medo da morte de uma forma muito introspectiva e particular, já que na casa delas há um muro que as separa da sociedade, atrás dele elas são apenas um casal de velhinhas que se amam, do lado de fora, são duas velhas estranhas, como elas mesmas falam. A história se passa apenas em um dia, e relata desde o acordar delas até a hora de dormir, uma escrita muito intimista, sensível e simples.

A terceira narrativa trata da descoberta da sexualidade de uma menina que, como a heteronormatividade manda, tenta gostar de um menino, mas não consegue, e encontra o amor e o companheirismo em uma pessoa com o mesmo sexo biológico. Os questionamentos que ela faz pra si própria são muito ingênuos, assim como o primeiro amor.

\section{Do social ao particular}

"Flor, flores, ferro retorcido" conta a história de uma criança, que em sua ingenuidade, não entende o motivo pelo qual sua vizinha é uma machorra. O primeiro parágrafo informa o leitor que trata-se de uma recordação, pois utiliza os verbos no passado e expressões como "naquele tempo", “era 1988" e "mas pensando agora". O ser criança está realçado pelas brincadeiras da personagem que adorava dançar músicas da Xuxa junto a sua amiga Celó́, andar de bicicleta e jogar bola.

A palavra machorra é falada entre os adultos em um dos almoços de domingo, o que inquieta a protagonista, ao serem questionados pela criança, eles mentem e depois a ignoram. Primeiramente, o adjetivo utilizado é extremamente ofensivo, assim, compreende-se o pensamento da vizinhança sobre pessoas LBGT, depois, o fato de não haver diálogo com a criança que apenas perguntou o significado da palavra e da inquietude dos adultos, revela que o assunto é tabu. Uma vez que quando há a troca de ideias há uma abertura para outros pensamentos, o que não ocorre aqui.

Embora seja uma palavra que remete a um estereótipo de lesbiana masculinizada, a forma que a personagem retrata sua vizinha é muito contrária a essa ideia.

No outro dia, fiquei plantada no muro para ver se a encontrava e, quando ouvi as alpargatas arrastadas se aproximando, me estiquei mais ainda por cima da cerca. E caí. Ela veio correndo me socorrer e me lembro de uma voz de fada me perguntando se eu estava bem, se tinha me machucado. (POLESSO, 2015. p.58) 
Em contrapartida, a mãe da menina ao saber o ocorrido age de forma grosseira, tratando sua filha com rispidez e violência, ao pegá-la pelo braço e tirá-la dali, não houve diálogo com a pessoa que ajudou a menina, o que reforça a ideia de intolerância. $\mathrm{O}$ tabu sobre outra forma possível de sexualidade que não a heterossexual segue no conto, pois a menina, ainda inquieta, procura por meio de perguntas à sua mãe entender o significado, e a resposta da mãe é apenas um tapa, que segundo a personagem, não doeu mas, a magoou. Ainda assim, com essa dor emocional e silenciamento por meio de violência, ela procura compreender, e recebe a resposta por parte da mãe, que isso é uma doença.

Sobre isso podemos supor que ou a mãe realmente crê ser uma doença, ou devido a todo um discurso científico do século XIX, os pensamentos das pessoas ainda são condicionados de alguma forma a pensar no lesbianismo como doença, desvio de conduta. Levando em conta que a história se passa no final dos anos 80, onde não havia tanto acesso a informação como no século XXI, pode-se acreditar tanto em uma quando na outra alternativa.

A menina em meio as suas reflexões, se indaga se a doença era contagiosa, tirando a parte da ingenuidade da criança, é sabido que há um discurso social, ainda hoje em dia, que homossexualidade é contagiosa, que o fato de alguém heterossexual conviver com uma pessoa homossexual, pode torna-la também homoafetiva. O que é um discurso muito preconceituoso, pois orientação sexual não pode ser influenciada dessa forma. Claro que a heteronormatividade nos influencia desde que nascemos, quando colocam brincos nas orelhas das meninas por exemplo, é uma maneira de marcar os seus corpos como sendo femininos, dando ao sexo biológico uma identidade de gênero que é socialmente construída com bonecas, exemplos midiáticos de relações heteronormativas, e ausência de homoafetividade. Mas de forma alguma a convivência com uma pessoa LGBT será "contagiosa", visto que não é uma doença, é uma outra forma legítima de sexualidade.

Há uma passagem do conto que mostra com clareza que o preconceito não nasce com o ser humano e sim se aprende.

Na manhã seguinte, eu fiz o que qualquer pessoa faria por um doente, ou o que eu entendia, na minha cabeça de criança, que qualquer pessoa faria: levei flores. Eu tinha visto na tevê. Peguei as flores que cresciam atrás da minha casa, flor de mato mesmo, umas amarelinhas e um punhado de margaridas. Fui até a mecânica bem cedo sem que ninguém me visse e deixei as flores na porta dela, dentro de um copo d'água. Deixei também um bilhete desejando melhoras e pedindo que, por favor, colocasse as flores num vaso e devolvesse o copo, porque minha mãe poderia dar falta. Ao meio-dia, quando voltava da escola, vi que as flores não estavam mais lá e sorri contente, porque ela as tinha recolhido. Entrei em casa feliz e saltitante, mas minha alegria foi quebrada em pedacinhos quando vi a cara da minha mãe, com o copo na mão, perguntando o que eu tinha na cabeça. Eu expliquei pra minha mãe que se a vizinha estava mesmo com machorra, seja lá que doença fosse aquela, 
alguém desejava ir lá e desejar boas melhoras. E foi o que eu fiz. Minha mãe me abraçou bem forte e disse que eu era uma ótima menina e que por isso eu não devia brincar perto da oficina. Eu perguntei qual e ela disse que era a da vizinha. (POLESSO, 2015. p. 60)

Esse trecho é bem significativo, pois a criança age naturalmente com a vizinha, com compaixão e boas intenções, ao pensar que ela realmente está doente, a simplicidade das flores, revelam que a menina deu o que pode e, que eram as flores de mato, o que importava na verdade era o desejo que a vizinha melhorasse. Quando a escritora coloca uma frase muito curta "E foi o que eu fiz." (POLESSO, 2015. p. 60), o leitor percebe, mais uma vez, a simplicidade de se tratar bem outra pessoa, além disso, o trecho também inicia com a menina dizendo que viu na televisão o exemplo e que achava que essa deveria ser a conduta de qualquer pessoa.

A mãe da menina ao proibi-la de brincar perto da oficina da vizinha, mesmo que não explicite na sua fala, tenta prevenir que sua filha seja contagiada com a doença da vizinha, o que retoma o pensamento do início do conto de que não pode haver diálogo sobre essa temática e que orientação sexual é contagiosa.

A doçura da vizinha novamente entra em cena, num trecho que a mãe se revela, outra vez, violenta.

Ela virou para mim com os cabelos molhados em cima do rosto e, com uma boca bem rosada e uns olhos carinhosos cor de mel, me disse que nunca esteve tão bem. Agradeceu as flores e se ajoelhou para me dar um beijo. Nessa hora, minha mãe apareceu e me puxou pelos cabelos. Ouvi o pai da Celoí dizendo não se preocupe, Flor.

Flor, o nome dela era Flor. E ela parecia uma flor mesmo. (POLESSO, 2015. p.61)

A imagem que o leitor de Flor é realmente muito doce, tal qual, segundo as regras patriarcais, as mulheres devem ser, os cabelos molhados revelam a vaidade de alguém que recém saiu do banho, a boca rosada, a feminilidade, os olhos de mel, refletem a doçura inerente ao gênero feminino, e o próprio nome, Flor, uma representação da beleza e fragilidade feminina perante a sociedade. Características que se opõe à imagem que uma palavra tão ríspida, machorra, provoca no leitor.

Posteriormente, no conto, a protagonista revela que tem apenas 8 anos de idade, e conversa com sua amiga de 11 anos sobre a doença da vizinha. Celoí mantém um diálogo franco com seu pai e, isso fica explicito quando ela diz que seu pai a orientou a não falar a palavra machorra, por ser ofensiva, e por poder conversar com seu pai, ela sabe o significado dessa palavra e tenta explicar para a protagonista usando bonecas como exemplos, o que a 
deixa confusa e, então partem para um teste, onde surgem perguntas como, preferencias, rosa ou azul, carrinho ou boneca, mas a menina não sabia responder, já que gostava de brincar de qualquer coisa, então, Celoí pergunta se gosta mais dela ou de um menino da rua, que pela descrição, não tinha nenhum envolvimento com a protagonista, e automaticamente a menina disse que gostava da Celoí, e ela então fala para a amiga que esse motivo a torna machorra também.

Toda a explicação sobre ser machorra é bem simplista, o que leva o leitor a compreender que não há mal nenhum em diálogos sobre esses temas com crianças, que devem ser tratados com naturalidade, já que são coisas normais da vida, porém, o teste aplicado na protagonista, fala sobre a construção social dos gêneros, separa coisas de menino e coisas de menina, revelando, assim, mais uma vez, o papel do feminino na sociedade, e que esse papel não pode ser vivido por uma mulher lesbiana, mesmo com todas as características femininas de Flor.

O próximo conto analisado é extremamente intimista, "Acorda Marília" é um conto sensível, de escrita leve e fluída, ainda que toque em outro tabu social, velhice, sexualidade na $3^{\mathrm{a}}$ idade, homoafetividade entre mulheres idosas. Ideias que são refutadas pela massa social, já que o único contexto que se admite a homossexualidade feminina, é quando ela é consumo pornográfico para o público masculino, dessa forma, elas devem ser jovens e se enquadrarem em um padrão de beleza pré-estabelecido pelas regras sociais, obviamente regidas pelo patriarcado.

A autora se propõe a quebrar com esse padrão de um forma muito sutil como pode-se ver no primeiro parágrafo:

Usa meias compridas até os joelhos porque, mesmo no verão, tem os pés frios. Senta na beirada cama e vai desenrolando as meias: panturrilha, canela, tornozelo e para. Volta a se endireitar. A barriga impede que se dobre sobre si. Respira fundo, estica bem os braços e termina. Dobra as meias e as coloca embaixo do travesseiro. São apenas para dormir. (POLESSO, 2015. p. 132)

As meias para dormir quebram com a dita sensualidade entre casais, os pés gelados também, visto que ao pensar no casal dormindo o pé gelado não é algo positivo, o romance está nos pés aquecidos, macios como veludos e sem meias mas, não aqui, pois são coisas retratadas de uma forma compreensiva e amorosa.

O leitor ao ler esse trecho, percebe que há uma dificuldade nos movimentos, e ainda não sabe o motivo. A própria escrita é vagarosa, lenta e fluída. A autora, em entrevista na internet, revelou que tem uma grande preocupação na forma da escrita, assim, quando o leitor 
se depara com "Volta a se endireitar." (POLESSO, 2015. p.132), uma frase curta e seca, com poucas palavras, antecedida por ponto e finalizada por um ponto final, com todo o contexto do parágrafo, visualiza e compreende a dificuldade motora, sabe que Marília precisa de um tempo, para respirar e voltar à tentativa de tirar sua própria meia dos pés.

A cumplicidade e a gentileza no trato uma com a outra é revelada quando é narrado que Marilia se acorda para preparar o café da manhã, e que sua companheira não se importa com o fato de ela não conseguir fazer silencio. Como rotina, finge estar dormindo, para que possa ser acordada com o café na cama, com um detalhe do desenho de uma flor em um guardanapo, pois sua companheira, ao lhe conhecer intimamente, fala que Marília jamais arrancaria uma. Em seguida, é exposto um problema de esquecimento adquirido com a idade avançada, Marilia não conseguiu fazer o café, o assunto é tratado com amor entre elas.

A fragilidade das duas, em decorrência da idade é apresentada, quando a escritora ressalta traços físicos como, mãos manchadas, cabelos brancos, cuidado ao beber o café para não queimar os lábios, comer o pão em pedaços pequenos para que não se engasgue, a dependência de um andador, falta de força e equilíbrio. Tudo isso, compartilhado entre elas na sua cama, logo de manhã cedo, sob os raios do sol ainda fracos, são detalhes muito ínfimos, que ganham uma proporção gigantesca, na forma com que Natalia consegue abordá-los, é perceptível que uma está sempre auxiliando a outra no que for necessário, isso parece ser o amor verdadeiro, depois de muitos anos de companheirismo.

Elas parecem se entender e conviver muito bem com a sua sexualidade, mas isso, apenas entre si, como pode-se notar no trecho:

E ficamos ali, atrás do muro que esconde nosso pátio da rua e que esconde a nossa vida das pessoas.

Ali naquela casa moram duas velhas. Moram ali faz anos essas duas velhas. Acho que elas têm alguma coisa, moram juntas faz anos. Ali na casa das velhas estranhas. (PPOLESSO, 2015. p. 134)

O muro serve de uma separação entre o púbico e o privado, como elas mesmas falam, o muro as esconde das pessoas, e de certa forma as protege, já que não poderiam ter toda a paz da casa delas se vivessem do outro lado do muro, em convivência direta com as pessoas, pois o mundo e os seres humanos ainda são muito preconceituoso, mesmo com uma história tão sensível e delicada como essa. Então, do muro pra fora fica a hostilidade, representada por falas, não marcadas graficamente, de pessoas aleatórias as chamando de velhas estranhas.

Para fechar a reflexão sobre esse conto, o artigo trará um trecho que sintetiza o amor dessas duas mulheres que fogem a todos os estereótipos sociais, como já mencionado. 
Eu morro de medo ainda e de novo e todos os dias rezo para que morramos juntas, porque eu não vou suportar ficar sozinha, e nem ela. Eu pensei em cuidar disso eu mesma. Pensei em fazer com calma, pensei em deitar com Marília, de meias, e no chá misturar uma dose que nos tranquilize e, com sorte, não acordaremos. [...]. Eu rezo para que sejamos juntas tão juntas como sempre fomos, agora e na hora da morte. (POLESSO, 2015. p. 136)

E a história se encerra, com a continuação da mesma rotina no domingo seguinte, com barulhos na cozinha e café da manhã na cama.

"Amora", além de ser o título da obra, também é um dos contos e nomeia a protagonista da sua história, uma menina que gosta muito de jogar xadrez e participa de competições pela sua escola. A sua idade exata não é revelada, mas se sabe que é uma criança, já que ganhou uma medalha, uma categoria a sua da sua, a infanto-juvenil.

A narradora da história conta que nesse dia ela se apaixonaria por Junior e, a partir de então, sua vida mudaria. Mas, ao chegar em casa, não fala uma palavra sobre o menino com seus pais, apenas sobre seu campeonato, será abordado posteriormente que sua conduta foi totalmente contrária de quando ela conhece Angélica. O que mostra que as sensações que a jovem sentiu eram totalmente passageiras e confusas pra uma criança.

Posteriormente, dois amigos vieram a convidar para ir brincar no fliperama, Amora ajeitou os cabelos dentro do boné, e a narradora ressalta que pareciam três meninos. Até aqui não se falou mais nada sobre Júnior, até que ela o encontrou no meio dos brinquedos, os dois sorriam um pro outro, jogaram juntos, mas o menino não a reconheceu, perguntou se a pessoa que jogava com ele tinha uma irmã que se chamava Amora, e assim, ela teve sua primeira decepção, descrita de uma forma muito poética, transformando o fogo em gelo.

Ao chegar em casa, correu até o espelho para tentar compreender o motivo de Júnior não a ter reconhecido, dessa forma,

\footnotetext{
Olhou-se no espelho. O boné, o cabelo preso, a camiseta de banda comprida demais, lisa, rente ao corpo, sem os relevos que outras meninas de sua idade já tinham, a bermuda jeans rasgada, o joelho ostentando casca de ferida, os chinelos pretos emoldurando as unhas compridas, rachadas. (POLESSO, 2015. p. 152)
}

Anteriormente a narradora havia alertado o leitor de que Amora parecia um moleque naquele dia, e isso foi confirmado pela descrição da narradora, pelo reflexo que a menina via no espelho e pelos pensamentos da própria Amora. Agora pensando que se trata de uma criança, isso não deveria ter problema nenhum, crianças brinca, se sujam, usam roupas confortáveis e, obviamente, não tem corpo definido. Contudo, a pressão social de fazer 
crianças se parecerem com adolescentes, criou todo esse problema. Outro ponto problematizador é que na realidade meninas, não podem se vestir, se comportar, e brincar como Amora faz, elas devem, usar vestidos, ter os cabelos soltos e brincar com outras meninas de casinha, aliás essa é a regra para que essa menina saiba seu papel no mundo, cresça compreendendo isso e, se torne uma boa esposa, dona de casa.

Esse embate entre o socialmente posto e o reflexo no espelho de Amora, cria um sentimento muito ruim na menina. $\mathrm{O}$ fato de ela perceber essas coisas no espelho, também é bastante significativo, pois o reflexo é fiel ao que ela é, mostra, sem esconder nada, seu verdadeiro eu, embora seja o que está, o reflexo também é interior.

Em um curto período de tempo, Amora mudou fisicamente e sentimentalmente, "Dois pequenos montes brotaram no seu peito, como que para proteger seu coração de meninamulher que se transmutava.” (POLESSO, 2015. p. 152), além disso, mudou a forma de vestir, tinhas as unhas pintadas e, agora era "Amora delicada, ora doce, ora áspera, sempre frágil, aquosa." (POLESSO, 2015. p. 253). Essa descrição da protagonista revela seu amadurecimento, seu crescimento biológico natural, como tentou se adequar às regras sociais de feminilidade, sua transformação emocional que lhe tornava por vezes forte, mas também frágil, ainda nessa parte há uma forte ligação do nome da menina com o da fruta, pois o texto traz cores avermelhadas, a doçura e a acidez, a fragilidade e aquosidade da fruta, características inerentes também à protagonista.

Junior entra em cena num próximo campeonato de xadrez e, novamente não reconhece Amora, porém, por motivos distintos da última vez, a menina coloca todos dentro de uma mesma categoria: desengonçados e nada atraentes. O menino não é classificado pra final, mas Amora e Angélica sim. Isso representa que, além do jogo de xadrez, o menino também perdeu a protagonista, e então, aparece outra personagem, Angélica, que havia ganhado todos os jogos, assim como Amora e, diferentemente de Junior.

Ao descrever a menina, a narradora diz que a protagonista notou as bochechas vermelhas e, atribuiu a isso a sensação de calor interno, descreveu que apenas o braço esquerdo conseguia ver, pois o outro estava escondido, Amora, por educação estendeu a mão direita para cumprimenta-la, e a menina estendeu a esquerda que mexia em umas peças do tabuleiro logo antes. A protagonista achou grosseiro por ainda não saber o motivo de a mão direita estar sempre escondida. A narradora enfatiza, que todo o processo feito por Angélica é unicamente com a mão esquerda. Ao descobrir que o motivo era que a outra menina não possuía a mão direita, Amora paralisou, se desconcentrou e perdeu o jogo, estendeu a mão 
esquerda para Angélica, pois agora sabia que não poderia cumprimenta-la com a direita, como havia tentado anteriormente.

Passaram a tarde juntas, à espera das medalhas, o que possibilitou que se conhecessem melhor. Angélica lhe confessou que ainda sentia sua mão quando Amora tocava com a ponta dos dedos a sua cicatriz. A menina revelou que sentia como se a protagonista pegasse na sua e, aquilo ficou na cabeça de Amora. "Achou estranho e ao mesmo tempo bonito que estivessem de mãos dadas." (POLESSO, 2015. p. 155). A partir desse instante todas coisas ruins provocadas pela desilusão de Júnior começaram a desfazer, e sentiu novamente todas as coisas boas "Amora sabia o que era aquilo, mas não entendeu como podia ser". (POLESSO, 2015. p. 155).

É perceptível que agora não era paixão, e sim, amor. O fato de Amora não compreender reafirma a construção heteronormativa que está implícita desde o início do conto. Pois, quando se apaixonou por Júnior, compreendeu na hora o que era, e não se questiono sobre, já que é um fato natural da vida, uma mulher deve se relacionar com um homem. Quando percebe o que sente por Angélica, Amora também identifica o que é, mas não consegue compreender, provavelmente por não saber, devido a sua pouca idade, ou exemplos sociais, que relação entre duas mulheres também é uma forma de manifestação de amor legítima e natural.

Ao retornar para sua casa, Amora, como adiantado anteriormente, agiu totalmente ao contrário de quando conheceu Júnior, seu único assunto, seu único interesse era falar sobre Angélica e não falou nada sobre o campeonato. O entusiasmo sentido por Amora é muito bem retratado na escrita, já que a leitura ocorre de uma forma mais rápida e freneticamente. Possibilitando ao leitor os mesmos sentimento da personagem. Foi extremamente necessária a primeira presença de Júnior e a frieza com que o encontro deles foi descrevido, pois, agora, com Angélica, tudo se contrapõe.

O conto termina com Angélica indo estudar na mesma escola da protagonista, assim, ela podia passar muito tempo segurando a mão imaginária de Angélica. É uma imagem muito forte essa, uma vez que o relacionamento delas, quando exposto socialmente, causaria incomodo nas pessoas ao seu redor. Assim, a mão imaginária é a forma perfeita para enfatizar como a sociedade não quer enxergar esse outro tipo de sexualidade. Elas só podem dar as mãos, porque ninguém enxerga. Assim, como anteriormente Marilia e sua companheira, só podem viver plenamente atrás do muro de suas casas, do lado fora, quando existem outras pessoas além delas, elas são hostilizadas. 


\section{Conclusões}

Com a leitura da obra, a análise e reflexão em cima dos contos, pode-se compreender a humanidade simples e natural presente nas personagens e nas narrativas, fato que se torna exatamente importante para a sociedade, visto que a literatura, embora seja ficcionalizada, reflete o mundo no qual se vive.

Assim, com leituras e discussões, as vivencias de outras sexualidades, que não as heterossexuais, passam a ser reconhecidas como naturais também. A literatura abre janelas para o novo, mas também ajuda a compreender o que se vive hoje e o que já se passou.

Além disso, ressalta-se a importância de consumir obras escritas pelas minorias políticas, para que dessa forma, possa haver uma divulgação dos temas tratados por elas e, consequentemente as discussões tão saudáveis para o amadurecimento social. Paloma (2016), na plataforma Valkirias, escreve sobre a diferença de escritos feitos por homens e por mulheres devido as suas vivências sociais. De forma que um homem escrevendo sobre a vivência feminina, mesmo com pesquisas, será uma escrita superficial, assim como também, alguém heterossexual que escreva uma história sobre homossexuais não será bem sucedido, entende-se o caso da "liberdade poética" para a criação literária, mas ainda assim, quem vive determinada realidade, sem dúvida terá maior autonomia para retratar tal assunto.

\section{Referências}

HOLLANDA, Heloísa Buarque de. Os estudos sobre mulher e literatura no Brasil: Uma primeira abordagem. Disponível em: <http://www.heloisabuarquedehollanda.com.br/osestudos-sobre-mulher-e-literatura-no-brasil-uma-primeira-abordagem-9/>. Acesso em: $04 \mathrm{de}$ jul. 2017

LESSO, Patrícia. Visibiliade e ação lesbiana na década de 1980: Uma análise a partir do grupo de ação Lésbico-Feminista e do boletim Chanacomchana. Gênero. Niterói, v.8, n.2, p. $301-333$, 1 sem. 2008

POLESSO, Natalia Borges. Amora. Porto Alegre: Não Editora, 2015

TV CÂMARA CAXIAS. Café com Letras - Natalia Polesso. Disponível em: <https://www.youtube.com/watch?v=IAdkR_L0bXE>. Acesso em: 03 de jul. 2017

VALKIRIAS. A importância de uma literatura feita por mulheres. Disponível em: <http://valkirias.com.br/importancia-literatura-feita-mulheres/>. Acesso em: 04 de jul. 2017 